\title{
Study on Water Engineering based on Mathematical Models
}

\author{
Guanqun Zhang \\ North China Electric Power University (Baoding), Huadian Road, Baoding, China \\ 1477107641@qq.com
}

Keywords: Freshwater resources, Fuzzy optimization approach, Sewage Treatment Plant Location

\begin{abstract}
Fresh water is the limiting constraint for development in much of the world. As we know, China is a water-shortage country, where the water available for each person is only a quarter of the world' s average level. Author put forward five water strategies to help the government meeting the water demands in the future.First, a water transport and storage model is proposed to cope with the unbalanced distribution of water resources, in which fuzzy optimization approach is taken to achieve the water allocation. A case study shows Tianjin has the largest amount of water rights within the four cities. Then, a Sewage Treatment Plant Location optimization model, which considers environment protection, the total investment, the local governmental planning, and the operation costs simultaneously, is established. A hybrid genetic algorithm with simulated annealing strategy in the generation gap is employed to solve the proposed model.
\end{abstract}

\section{Introduction}

According to the figure of water resources distribution of China ${ }^{1}$, we can see that water resources distribution is imbalanced in China's different districts. Furthermore, the shortage of fresh water is also a long-term problem. Our objective is to use all kinds of methods to save water and improve the utilization rate of water. Make water resources distribution balanced is another target for the sake of using water resources better. We'll begin our mathematical analysis and develop a detailed model to find water strategy using data analysis and processing in the following sections.

\section{Water Transfer Process and Water Rights Issues in the Process ${ }^{2}$}

Determine the weights. To determine the weights of every factor and indicator:

Assume the system goal set as $T=\left\{T_{1}, T_{2}, T_{3}, \cdots, T_{m}\right\}$, we will precede binary comparative importance ranking to the goal in the goal set or the index under various actors, then we can get consistency scale matrix of binary comparative importance ranking:

$$
P=\left[\begin{array}{cccc}
p_{11} & p_{12} & \cdots & p_{1 m} \\
p_{21} & p_{22} & \cdots & p_{2 m} \\
\cdots & \cdots & \cdots & \cdots \\
p_{m 1} & p_{m 2} & \cdots & p_{m m}
\end{array}\right]=\left(p_{i j}\right)_{m \times m} \quad p_{i j}=\left\{\begin{array}{c}
0, T_{i} \text { is important to } T_{j} \\
0.5, T_{j} \text { and } T_{i} \text { are the same } \\
1, T_{j} \text { is important to } T_{i}
\end{array}\right.
$$

Relative membership degree vector of the target set: $w_{t}=\left\{w_{1}, w_{2}, w_{3}, \cdots, w_{m}\right\}$.

Qualitative indicators and quantitative indicators. Assume the system scheme set as $D=\left\{d_{1}, d_{2}, \cdots, d_{n}\right\}$, where $d_{i}$ is the i-th scheme in the system scheme set. If the system has $\mathrm{m}$ indicators, $\mathrm{K}$ of them are quantitative indicators, $\mathrm{M}-\mathrm{K}$ of them are qualitative indicators. We will proceed binary comparative importance ranking to qualitative indicators, then we can get the relatively optimal membership matrix $\phi_{1}$ of qualitative index to scheme set.

There are two effects that quantitative indicators have on scheme set. They are more big, more optimal and more small, more optimal. Assume there are S quantitative indicators that the indicators are more big, more optimal; and $\mathrm{T}$ quantitative indicators that the indicators are more small, more optimal. So we can get $\mathrm{S}+\mathrm{T}=\mathrm{K}$. We get the relative optimal membership degree matrix $\varphi_{1}$ according to 
quantitative indicators that the indicators are more big, more optimal; and the relative optimal membership degree matrix $\varphi_{2}$ according to quantitative indicators that the indicators are more small, more optimal. We merge $\varphi_{1}$ with $\varphi_{2}$, then we can get quantitative objective on optimal membership degree matrix $\varphi$.

Comprehensive relative optimal membership. Assume the scheme attaches to ideal optimal scheme through relative optimal membership $V_{j}$. G and B are respective on behalf of ideal optimal scheme and ideal inferior scheme. The generalized weighted distance between J program and the both scheme above:

$$
d_{j g}=\sqrt[p]{\sum_{i=1}^{m}\left(w_{i}\left|\phi_{i j}-1\right|\right)^{p}} \quad d_{j b}=\sqrt[p]{\sum_{i=1}^{m}\left(w_{i}\left|\phi_{i j}-0\right|\right)^{p}}=\sqrt[p]{\sum_{i=1}^{m}\left(w_{i} \phi_{i j}\right)^{p}}
$$

Where $\mathrm{P}$ is parameter, when $\mathrm{P}=1$, the distance above is called as Hamming distance; when $\mathrm{P}=2$, the distance above is called as Euclidean distance. Then we can get the optimal solution model:

$$
v_{j}=\frac{1}{1+\left(\frac{d_{i j}}{d_{j b}}\right)^{2}}
$$

We calculate average value of the results when $\mathrm{P}=1$ and $\mathrm{P}=2$,it is the comprehensive relative optimal membership of the scheme. Do normalization processing to the comprehensive relative optimal membership vector quantity of the scheme, then we can get the weighted value of goal.

Application example. It can finish water diversion project from Jiangsu Yangzhou Yangtze river main stream to North China basically in 2025.

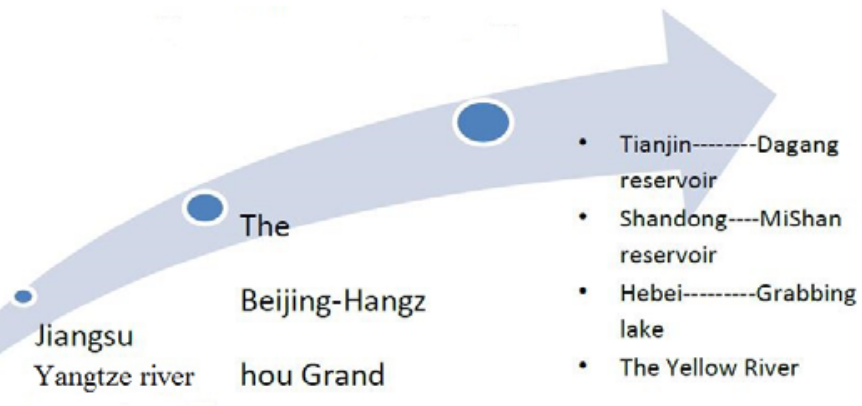

Fig. 1 The storage of the water

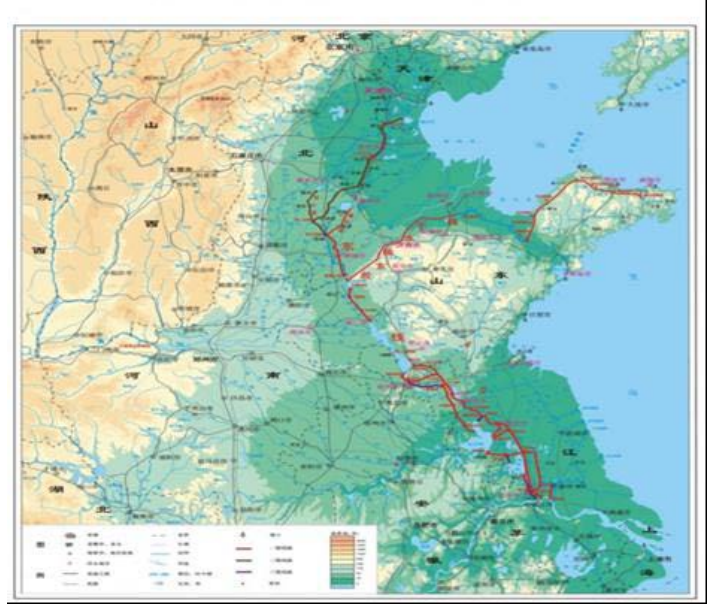

Fig2. The project of Water Transfer from South to North

The scope is Shandong, Tianjin, Hebei province, the Yellow River. So the diversion of water rights deploy in the four places initially. Assume the scheme set is 
$D=\left\{d_{1}, d_{2}, d_{3}, d_{4}\right\}=\{$ Shandong,Tianjin,Hebei province,the Yellow River $\}$.

Table1: Total system target weight and relative optimal membership

\begin{tabular}{|c|c|c|c|c|c|c|c|c|}
\hline \multirow[b]{2}{*}{$\begin{array}{c}\text { Target layer } \\
\text { A }\end{array}$} & \multirow[b]{2}{*}{$\begin{array}{c}\text { Factor layer } \\
\text { B }\end{array}$} & \multirow[b]{2}{*}{$\begin{array}{c}\text { Factor layer } \\
\text { weight }\end{array}$} & \multirow[b]{2}{*}{$\begin{array}{c}\text { index layer } \\
\text { C }\end{array}$} & \multirow[b]{2}{*}{$\begin{array}{l}\text { index } \\
\text { layer }\end{array}$} & \multicolumn{4}{|c|}{ Relative membership degree } \\
\hline & & & & & $\begin{array}{l}\text { Shand } \\
\text { ong }\end{array}$ & Tianjin & Hebei & $\begin{array}{c}\text { The } \\
\text { Yellow } \\
\text { River }\end{array}$ \\
\hline \multirow{11}{*}{$\begin{array}{c}\text { The water rights } \\
\text { regional initial } \\
\text { Configuration in } \\
\text { Water diversion } \\
\text { project }\end{array}$} & \multirow{4}{*}{$\begin{array}{l}\text { Fairness factor } \\
\text { B1 }\end{array}$} & \multirow{4}{*}{0.304} & $\mathrm{C} 1$ & 0.232 & 1.000 & 0.869 & 0.437 & 0.267 \\
\hline & & & $\mathrm{C} 2$ & 0.187 & 1.000 & 0.844 & 0.747 & 0.322 \\
\hline & & & C3 & 0.231 & 0.031 & 0.094 & 0.457 & 1.000 \\
\hline & & & $\mathrm{C} 4$ & 0.348 & 1.000 & 0.899 & 0.151 & 0.101 \\
\hline & \multirow{2}{*}{$\begin{array}{l}\text { Efficiency } \\
\text { factors B2 }\end{array}$} & \multirow{2}{*}{0.263} & $\mathrm{C} 5$ & 0.525 & 0.992 & 0.983 & 0.394 & 0.498 \\
\hline & & & C6 & 0.475 & 0.987 & 0.881 & 0.462 & 0.201 \\
\hline & \multirow{2}{*}{$\begin{array}{l}\text { Sustainable } \\
\text { factors B3 }\end{array}$} & \multirow{2}{*}{0.212} & $\mathrm{C} 7$ & 0.651 & 0.862 & 0.996 & 0.379 & 0.182 \\
\hline & & & $\mathrm{C} 8$ & 0.349 & 0.617 & 0.681 & 1.000 & 0.929 \\
\hline & \multirow{3}{*}{$\begin{array}{l}\text { Coordination } \\
\text { factors B4 }\end{array}$} & \multirow{3}{*}{0.131} & C9 & 0.175 & 0.333 & 0.429 & 1.000 & 0.538 \\
\hline & & & $\mathrm{C} 10$ & 0.123 & 1.000 & 0.333 & 0.176 & 0.250 \\
\hline & & & C11 & 0.702 & 0.608 & 0.816 & 0.554 & 1.000 \\
\hline \multicolumn{3}{|c|}{ Initial weight distribution } & & & 0.384 & 0.392 & 0.124 & 0.100 \\
\hline
\end{tabular}

So we can get water diversion water rights' weight:

\{Shandong, Tianjin, Hebei, the Yellow River $\}=\{0.384,0.392,0.124,0.100\}$.

Set the project total investment as $\mathrm{M}$ (one hundred million $¥$ ), including:

Water engineering investment: M1 River training works: M2

Water Conveyance Project Investment: M3

$\mathrm{M}=\mathrm{M} 1+\mathrm{M} 2+\mathrm{M} 3=266.611+86.673+1013.605=136.6889$ billion $¥$

According to "who share, who benefits" principle, the costs of each district are follows:

$S_{\text {Shandong }}=1366.889 \times 0.384=52.4885$ billion $¥ \quad S_{\text {Hebei }}=1366.889 \times 0.124=16.9494$ billion $¥$

$S_{\text {Tianjin }}=1366.889 \times 0.392=53.582$ billion $¥ \quad S_{\text {The Yellow River }}=1366.889 \times 0.100=13.6689$ billion $¥$

The project is expected to increase water supply for 7.948 billion/m3, regions get water right quantity:

$Q_{\text {Shandong }}=79.48 \times 0.384=3.052$ billion $/ \mathrm{m} 3$

$Q_{\text {The Yellow River }}=79.48 \times 0.100=794.8$ million $/ \mathrm{m} 3$

$Q_{\text {Tianjin }}=79.48 \times 0.392=3.1156$ billion $/ \mathrm{m} 3$

$Q_{\text {Hebei }}=79.48 \times 0.124=985.6$ million $/ \mathrm{m} 3$

This kind of deploy can remit effectively Shandong peninsula and the LuBei areas' problem of the shortage of water; Moreover, it creates conditions for Tianjin's emergency; at the same time, it solves the Yellow River problem of the decrease of the water.

\section{Sewage Treatment Plant Location}

Introduction. Our above discussion demonstrates water needs and population in each province (standing for different district)in the future, our principal concern now is how to meet the projected water needs. Here, I formulate a sewage treatment plant location model to simulate and settle with the problem.

Analysis of problem. As a crucial part of prophase preparatory stage, site selection of the sewage water treatment plant concerns scheme rationality of the whole project. It is necessary to comprehensively consider influence factors as the local planning, environmental protection, the processing technology and the total cost of investment. 
The foundation of the model. In terms of the sewage system in a given area, a network involving all of the towns, all possible choices of treatment plant location, and all possible laid network arc is adopted. Direction of the arc depends only on the flow direction of the sewage. Suppose Hi as the sewage quantity of node i yielded yearly. It is obvious that $h_{i} \geq 0$.If node $\mathrm{i}$ is a potential node to build one treatment plant, suppose one non-negative variable $x_{i}$ as the sewage water purified yearly after the establishment of the treatment plant. Obviously $x_{i}$ is unknown, however it can be solved in accordance with some optimization principle. If $x_{i}$ is worked out to be zero, then this location is not suitable to build treatment plants. The arc from node $\mathrm{i}$ to node $\mathrm{j}$ is written as $(i, j)$, whose yearly sewage flow is regarded as $y_{i j}$. If the ultimate solution of $y_{i j}$ is zero, then no transfer pipe should be built here. $b_{i j}$ stands for the maintenance charge of a part of the pipe related to node i, $a_{i}$ while stands for the maintenance charge of one sewage treatment factory. $b_{i j}$ is a function of $y_{i j}$, and $a_{i}$ is a function of $x_{i}$. The forms of the two function are already acknowledged. The network described above is recorded as $G=(N, A)$, where $N$ represents the node set and $A$ is the directed arc set.

Finally, we are able to formulate a model to seek the best location and objective function: $c=\sum_{i \in N} a_{i}\left(x_{i}\right)+\sum_{(i, j) \in A} b_{i j}\left(y_{i j}\right)$,

under constraint conditions that

$$
\left\{\begin{array}{l}
x_{i} \leq \sum_{i \in N} h_{i} \\
x_{i}+\sum_{j \in N,(i, j) \in A} y_{i j}-\sum_{k \in N,(k, j) \in A} y_{i j}=h_{i} ; \\
y_{i j} \leq x_{i} \forall i \in N, y_{i j} \geq 0, \forall(i, j) \in A ; x_{i} \geq 0, \forall i \in N
\end{array}\right.
$$

reach the Minimum. This group of constraints represents the conservation of water in each node. Because each node has a corresponding constraint, so the total number of constraints and junction points are equal, which draws a significant importance to our optimal analysis.

Solution to the model. We can evaluate this problem as an NP problem, so solutions obtained via traditional methods cannot prove to be the most optimal. Therefore we calculate the ultimate solution by combining Simulated Annealing and Genetic Algorithm. Explicit steps are as follows:

Step1 Initialize control parameters: Population size sizepop, the largest time of evolution MAXGEN, cross probability $\mathrm{P}$, mutation probability $P_{m}$, annealing initial temperature $T_{0}$, temperature cooling coefficient $k$, energy conversion formula $E$, end temperature $T_{\text {end }}$.

Step2 Random initialization, and generate the initial population Chrom. For each individual, calculate the fitness value $f_{i}$ using the reciprocal of the objective function, of which $i=1,2, \cdots$, sizepop .

Step3 Design cycle count variable gen $=0$.

Step4 Implement genetic operation: selection, crossover and compile to the Chrom group. Calculate each individuals fitness value $f_{i}^{\prime}$.If $f_{i}^{\prime}>f_{i}$, have the new individual replace old individual; Or otherwise the probability $P=\exp \left(f_{i}-f_{i}^{\prime}\right) T$. We accept the new individual, and abandon the old individual.

Step5 If gen i MAXGEN, then gen = gen + 1switch to step 6.

Step6 If $T_{i}<T_{e} n d$, then the algorithm is successfully concluded. Return the global optimal solution. Otherwise do cooling operation $T_{i+1}=k T_{i}$ and switch to step3.

After numerical calculation above, we can get access to a set of optimized solutions. 


\section{References}

[1]http://tupian.baike.com/a0_13_50_19300000332127132989502522741_jpg.html

[2]Aiping Guan, Ke Wang. (2011). Study on initial allocation of water rights for South--North Water Diversion Projec. Yangtze River, 42(3), 57-61

[3]Zhouhu Wu, Haitao Qiao, Shasha Fu, Yuhua Zhou. (2006). Effect of South-ti-North Water

Transfer on Environment of Nansi Lake and Defending Strategies. 27(1) 1-7.

[4]Peisheng Yuan. The Running Cost analysis of Town Sewage Treatment Plant. ENVIRONMENTAL SCIENCE AND MANAGEMENT (2008) 33(1) 107-109.

[5]https://people.uwec.edu/piercech/desalination/MSF.html

[6]http://www.wwindea.org/technology/ch05/en/5_2_1.html

[7]Anthony Atkinson, Marco Riani, Robust Diagnostic Regression Analysis, Spring Press, 2000.

[8]Aiping Guan, Ke Wang. Study on initial allocation of water rights for South--North Water Diversion Projec. Yangtze River, 42(3) (2011) 57-61. 